acid containing dissolved $\mathrm{N}_{2} \mathrm{O}_{4}$, and the lower layer of aqueous $\mathrm{HNO}_{3}$ more dilute than that originally taken for treatment.

The above experiment was repeated and the condensed layers treated with a slow stream of oxygen to remove all traces of the $\mathrm{N}_{2} \mathrm{O}_{3}$.

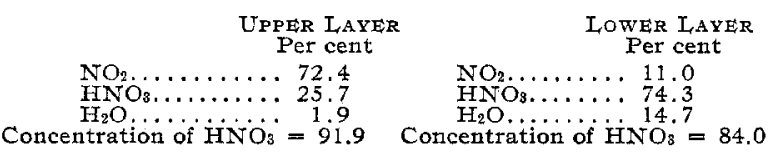

Having shown the applicability of this process to the direct preparation of strong nitric acid from nitrogen dioxide and oxygen, attempts were made to prepare strong nitric acid from a mixture of $\mathrm{NO}_{2}$, air and oxygen. For this purpose oxygen was introduced along with the air supply and the concentration of $\mathrm{NO}_{2}$ in the gas mixture was maintained at a low figure, approximating technical conditions of operation in denitrator towers, viz., 20 per cent of the air content.

Air rate $=60 \mathrm{cc}$. per min. (at $30^{\circ} \mathrm{C}$ ) saturated with water vapor Oxygen rate $=60 \mathrm{cc}$. per min. saturated with water vapor at $18^{\circ} \mathrm{C}$ $\mathrm{NO}_{2}$ rate $=60 \mathrm{cc}$. per min. dry

Temperature of cooling spiral $=-8^{\circ} \mathrm{C}$

$$
\begin{aligned}
& \text { Analysis of the Condensate } \\
& \text { HNOs. . . . . . . . 85.4 } \\
& \mathrm{NO}_{2} \mathrm{~N}_{2} \ldots \ldots \ldots \ldots \ldots \ldots \ldots \ldots \%{ }^{6.1} \\
& \text { Concentration of nitric acid }=91.2
\end{aligned}
$$

The conditions necessary to obtain concentrated acid from weaker gases, e. g., those containing Io to I3 per cent of $\mathrm{NO}_{2}$ by volume, such as are obtained in ammonia oxidation processes, were next examined. From vapor pressure data the point of commencement of liquefaction of nitrogen dioxide of various concentrations has been determined as follows:

$\begin{array}{cc}\mathrm{NO}_{2} \text { in Gas } & \begin{array}{c}\text { Commencement of } \\ \text { Per cent }\end{array} \\ 50 & \mathrm{C} \text {. } \\ 25 & \pm 8 \\ 20 & =12 \\ 15 & =18 \\ 10 & =23 \\ 5 & -35 \\ 1 & -60\end{array}$

It was at once evident that the direct condensation of dry dilute $\mathrm{NO}_{2}$ required extremely low temperatures for operation. Provided, however, a more easily condensable constituent of the gas phase be present which is a solvent for nitrogen dioxide, the removal of $\mathrm{NO}_{2}$ can be effected at the temperature of liquefaction of the solvent. In the present series of experiments this solvent was dilute nitric acid produced from the water vapor present in the gases.

The following method of procedure was adopted: A I 2 per cent $\mathrm{NO}_{2}$-air mixture obtained from a small platinum gauze ammonia oxidation converter was cooled quickly to $20^{\circ} \mathrm{C}$. in order to separate out the excess of water, over and above that necessary for the completion of the equation

$$
{ }_{2} \mathrm{~N}_{2} \mathrm{O}_{4}+{ }_{2} \mathrm{H}_{2} \mathrm{O}+\mathrm{O}_{2}={ }_{3} \mathrm{HNO}_{3} \text {. }
$$

,This gas was then led into cooling vessels immersed in freezing mixtures of ice and salt in order to condense out the nitric acid formed. With a flow rate of $\mathbf{I} .5$ liters of gas per min., a condensate of $6 \mathrm{I.2}$ per cent, increasing to $78 . \mathrm{I}$ per cent acid strength at $-10^{\circ} \mathrm{C}$., was obtained.
SUMMARY

$\mathrm{I}$-The rate of absorption of nitrogen dioxide by water and nitric acid solutions follows a monomolecular law. In aqueous solutions the reaction is pseudomonomolecular, being a process of physical solution, the rate depending on the partial pressure of $\mathrm{NO}_{2}$ in the gas phase. In strong acid solutions the reaction is a true chemcal monomolecular reaction, the rate depending on the concentration of the $\mathrm{N}_{2} \mathrm{O}_{4}$. An inversion of the temperature coefficient of absorption occurs at io per cent nitric acid strength.

2-The limitation of acid produced in nitric acid absorption towers to concentrations of 64 per cent nitric acid is due to the reduction of nitric acid by nitrous anhydride produced in solution, according to the reversible equation

$$
{ }_{2} \mathrm{HNO}_{3}+\mathrm{N}_{2} \mathrm{O}_{3} \rightleftarrows \mathrm{H}_{2} \mathrm{O}+{ }_{2} \mathrm{~N}_{2} \mathrm{O}_{4} \text {. }
$$

The equilibrium constant of this equation at ordinary temperatures is approximately $\mathrm{K}=0.8 \mathrm{I}$.

3 - The production of nitric acid exceeding 64 per cent in strength is possible, provided that the $\mathrm{N}_{2} \mathrm{O}_{3}$ be continuously converted into nitrogen dioxide by agitation with oxygen.

4-The production of strong nitric acid may be accomplished by a process of refrigeration of a gas mixture containing suitable proportions of nitrogen dioxide, water vapor, and oxygen.

\section{THE PRODUCTION OF HYDROCHLORIC ACID FROM CHLORINE AND WATER}

\section{By H. D. Gibbs}

Colór laboratory, Bureau of Chemistry, Washington, D. C. Received October 28, 1919

Since the utilization of the potentially large production of chlorine brought about through war requirements offers some difficulties, pending the establishment of an equilibrium by adjustment of the chemical industries from a war to a peace basis, the economic conversion of chlorine into hydrochloric acid has been investigated.

Early in the study of elementary chemistry one learns that chlorine reacts with water in the sense of the expression

$$
\mathrm{Cl}_{2}+\mathrm{H}_{2} \mathrm{O} \rightleftarrows \mathrm{HCl}+\mathrm{HOCl}
$$

and that the hypochlorous acid decomposes thus,

$$
\mathrm{HClO} \longrightarrow \mathrm{HCl}+\mathrm{O} \text {. }
$$

Owing to the instability of hypochlorous acid in the presence of hydrochloric acid, the first reaction progresses to a very limited extent and the production of the end-products, oxygen and hydrochloric acid, is greatly accelerated by light. This accounts for the fact that aqueous solutions of chlorine eventually become aqueous solutions of hydrochloric acid upon standing in the laboratory, and should therefore be protected from the light. A catalyst that will speed these reactions and afford a cheap method of conversion of chlorine and water into hydrochloric acid and oxygen could be made the basis of a valuable commercial process.

This is the reversal of the Deacon process. The 
catalyst for the Deacon process is usually described as a rough surface impregnated with cupric chloride, although many other substances, such as the chlorides of iron, nickel, cerium, or alunite ${ }^{1}$ may be employed. Lewis ${ }^{2}$ has described a careful investigation of the equilibrium of the Deacon process, employing the first of these catalysts, and it is evident that the reversal, producing hydrochloric acid and water, is best carried out at high temperatures. The equilibrium constant

$$
\mathrm{K}=\frac{p^{1 / 2 \mathrm{Cl}_{2}} p^{1 / 2 \mathrm{H}_{2} \mathrm{O}}}{p^{\mathrm{HCl} 1} p^{1 / 4 \mathrm{O}_{2}}}
$$

decreases from 4.15 at $352^{\circ} \mathrm{C}$. to 2.40 at $4 \mathrm{r9} 9^{\circ} \mathrm{C}$. as shown from his experimental work, and to 0.133 at I $537^{\circ} \mathrm{C}$. as calculated.

A catalyst which will produce the desired products, hydrochloric acid and oxygen, to a satisfactory degree has not as yet been developed. This paper merely describes the present state of the work when charcoal is employed as a catalyst.

\section{HYDROCHLORIC ACID FORMED BY THE UNION OF HYDROGEN AND CHLORINE}

Processes have been devised for converting chlorine into hydrochloric acid by union with hydrogen. A process at low temperature was patented by Pataky who states that the combination of hydrogen and chlorine may be effected in a quiet and continuous manner by passing the gases in molecular proportion over coarsely pulverized charcoal, controlling the temperature by means of a water bath. Conroy ${ }^{4}$ in commenting upon Pataky's process for getting rid of an excess of chlorine states:

The process is intended as an adjunct to the manufacture of chlorine and alkali by electrolysis, but it is far from likely that it will ever come into extended use.

Garner and Clayton ${ }^{5}$ obtained a patent on the manufacture of hydrochloric acid by the union of dry chlorine and dry hydrochloric acid in presence of wood charcoal at temperatures above $340^{\circ} \mathrm{C}$., and they also provide a slight modification in the procedure to be employed if moisture is present. They state:

As hereinbefore indicated, the gases can advantageously be dried before their admission into the chamber containing the catalyzer, for the reason that if moisture is present the reaction proceeds too violently when equal volumes of hydrogen and chlorine are used. We have discovered, however, that the reaction will still proceed smoothly and without explosive violence even though moisture is present, provided the hydrogen is used in excess, such as 50 parts of hydrogen by volume to 35 parts of chlorine by volume, or by using any larger excess of hydrogen. In fact, under such conditions, the temperature required for the reaction is about $340^{\circ} \mathrm{C}$.

There are three claims, the first being:

The method of making hydrochloric acid which comprises causing hydrogen and chlorine to react at a temperature of not below about $340^{\circ} \mathrm{C}$. in the presence of wood charcoal, moisture being present in the reacting gases and the hydrogen being employed in excess, and recovering the hydrochloric acid thus formed, substantially as described.

1 U. S. Patent $1,311,175$ (1919)

J. Am. Chem. Soc., 28 (1906), 1380.

3 D. R. P., 114,219 (1899); Brit. Patent 1,831 (1900).

4 J. Soc. Chem. Ind, 21 (1902), 304.

B U. S. Patent $1,220,411$ (1917), assigned to Metals Research Company of New York, N. Y.
These patents differ from each other essentially in the factor of temperature.

An excess of chlorine has recently been taken care of in at least one plant by combustion with hydrogen at high temperature. The heat was removed by water cooling the combustion apparatus.

\section{HYDROCHLORIC ACID FORMED BY THE REACTION BETWEEN CHLORINE AND WATER}

During the investigation in this laboratory ${ }^{1}$ of the absorption of chlorine by various kinds of charcoal, it was found that the moisture content of the gases coming in contact with the charcoal at room temperature greatly influenced not only the rate of absorption but also the nature of the phenomenon. There are other important factors that will be discussed later in this paper. When the chlorine-air mixture is dry the chlorine is removed from the air and is retained by the charcoal, while with moist gases a chemical change takes place that is manifested by a reaction between the water and the chlorine in the sense of the equation

$$
{ }_{2} \mathrm{Cl}_{2}+{ }_{2} \mathrm{H}_{2} \mathrm{O}+\mathrm{C}={ }_{4} \mathrm{HCl}+\mathrm{CO}_{2} \text {. }
$$

The reaction is very satisfactory in that all of the chlorine may be converted into hydrochloric acid but very disappointing in that the oxygen does not appear as such, but, as might be predicted, unites with the carbon. The formation of hydrochloric acid has been found to proceed over a very wide temperature range above $80^{\circ} \mathrm{C}$, preferably between $80^{\circ}$ and $200^{\circ}$, and large quantities of chlorine can be handled in a comparatively small apparatus. ${ }^{2}$

The best procedure is to blow the steam and chlorine through a large bed of charcoal of the character used for absorbing gases-coconut charcoal, ivory nut charcoal, and other varieties especially treated-and at the same time small quantities of air may be admitted to assist in sweeping out the products of the reaction. The process is highly exothermic and the excess of water and air carries off the heat generated in the catalytic mass.

After this process was developed on a laboratory scale it was found that it had been partially described in the literature and that two investigators had patented the process at two different temperature ranges above I00 $0^{\circ}$. Lorenz ${ }^{3}$ states:

In many technical processes, such as in the electrolytic production of metals from their chlorides, chlorine is produced as a by-product.

In most cases, however, it is not possible to render the chlorine thus produced commercially available.

It is therefore desirable to convert such chlorine into a commercially valuable compound.

According to my present invention I effect this in converting the chlorine into hydrochloric acid by passing it together with steam through a clay retort filled with coke, charcoal, or anthracite, and heated to a low red heat. By this means chemically pure hydrochloric acid is obtained.

I have found that in the same manner bromine can be converted into hydrobromic acid, namely, by passing vapors of bromine together with steam through a clay retort filled with

1 G. S. Bohart and E. Q. Adams, "Some Aspects of the Behavior of Charcoal with Respect to Chlorine," $J$ Am. Chem. Soc., 42 (1920), 523. I am indebted to them for much data and the curves.

2 U. S. Patent pending.

Brit. Patent 25,073 (1894). 
coke, charcoal, anthracite or the like, and heating to a low red heat.

The production of hydrochloric acid from chlorine and of hydrobromic acid from bromine by passing the chlorine or bromine together with steam through vessels filled with coke, charcoal, or anthracite heated to a low red heat, the resulting hydrochloric acid or hydrobromic acid being then separated from the other resulting gases by condensation substantially as described.

\section{Peter ${ }^{1}$ states:}

According to the process of this invention, hydrochloric acid is produced from chlorine by means of water-vapor. I believe that I am the first to discover that by properly proportioning the chlorine and water-vapor, hydrochloric acid can be produced at low temperature and the first to provide means by which the proper proportioning may be determined and accomplished.

In carrying out the process of the present invention, the chlorine in contact with water or water-vapor forms hydrochloric acid and liberates oxygen, and in order to accelerate the latter reaction it is desirable to have present a substance or substances to take hold of the oxygen, as, for example, carbon or sulfur, and I prefer to use carbon in the form of charcoal or coke.

By the process of the present invention, the chlorine may be converted quantitatively into hydrochloric acid at a temperature as low as $200^{\circ} \mathrm{C}$. and the chlorine may be converted into hydrochloric acid at temperatures just above boiling point of water.

There are seven claims in the patent, the broadest being: "A process for making hydrochloric acid comprising the conversion of chlorine into hydrochloric acid by means of water-vapor and carbon at a temperature lower than red heat."

Other claims fix the temperature range "between the boiling point of water and red heat" although there is nothing to show that the inventor considered the patent operative below $200^{\circ}$.

It is to be noted that the only difference of any importance in these patents is the reaction temperature.

In regard to the mechanism of the reaction, Loren $z^{2}$ points out that it has been known for many years that chlorine and water do not react in the dark at $10 \mathrm{w}$ temperatures, unless there be present some substance to react with the oxygen, such as boron, phosphorus, sulfur, selenium, iodine, phosphorous acid, sulfurous acid, or an oxidizable carbon compound. He states that the reaction goes quantitatively according to the equation

$$
{ }_{2} \mathrm{Cl}+\mathrm{H}_{2} \mathrm{O}+\mathrm{C}={ }_{2} \mathrm{HCl}+\mathrm{CO} \text {. }
$$

Naumann and Mudford, ${ }^{3}$ and Natumann ${ }^{4}$ point out that the reaction

$$
{ }_{2} \mathrm{H}_{2} \mathrm{O}+\mathrm{C}=\mathrm{CO}_{2}+{ }_{2} \mathrm{H}_{2}
$$

goes on below $600^{\circ} \mathrm{C}$. and that the reaction between chlorine, water, and carbon should be expressed

$$
{ }_{2} \mathrm{Cl}_{2}+{ }_{2} \mathrm{H}_{2} \mathrm{O}+\mathrm{C}={ }_{4} \mathrm{HCl}+\mathrm{CO}_{2} \text {, }
$$

and that any carbon monoxide formed arises from the decomposition of the carbon dioxide in presence of carbon. Moreover, any carbon monoxide formed will be oxidized according to the equation

$$
\mathrm{Cl}_{2}+\mathrm{H}_{2} \mathrm{O}+\mathrm{CO}={ }_{2} \mathrm{HCl}+\mathrm{CO}_{2} \text {. }
$$

They show that at higher temperatures, above $400^{\circ}$ C., an excess of water-vapor results in formation of carbon dioxide, carbon monoxide, and hydrogen. The thermal relations of the various reactions involved are

1 U. S. Patent $1,229,509$ (1917), assigned to Royal Baking Powder Company of New York, N. Y.

$2 Z$. anorg. Chem, $10(1895), 74$

s Ber., 30 (1897), 347.

4. angew, Chem., 1897, 197. discussed and the conclusion is reached that, since the balance is highly exothermic, a valuable process might be evolved.

It is possible that the catalytic action of the charcoal is of greater importance than indicated in the above work and that the reaction between water and chlorine is catalyzed by the charcoal in the sense of the equation

$$
\mathrm{Cl}_{2}+\mathrm{H}_{2} \mathrm{O}={ }_{2} \mathrm{HCl}+\mathrm{O} \text {, }
$$

the active oxygen liberated disappearing simultaneously through union with the carbon. The fact that the reaction has a very appreciable speed at room temperature, and even as low as $0^{\circ}$, offers some support of this theory. The necessary energy is supplied to the reaction by the combustion of the charcoal.

INFLUENCE OF TEMPERATURE-The four curves of Fig. I show the effect of temperature at four different ranges, $0^{\circ}$, I $2^{\circ}, 25^{\circ}$, and $37.5^{\circ}$, upon the amount of the chlorine converted into hydrochloric acid, all other conditions being constant.

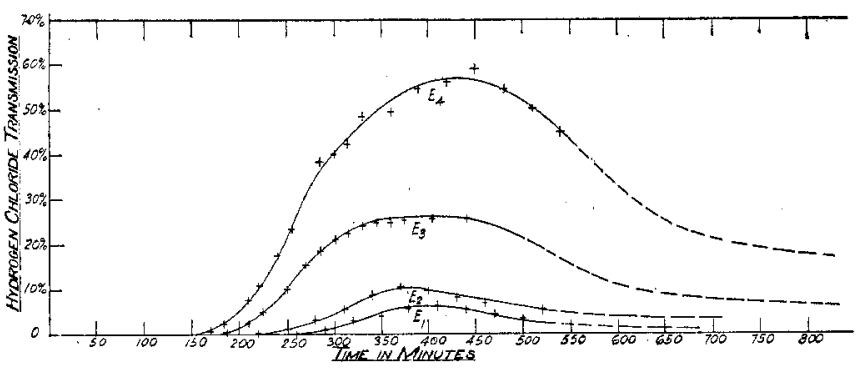

Fig. 1-The Production of Hydrogen Chloride at, Four Different TEMPERATURES

Constants: Catalyst, Charcoal $\mathrm{E}_{\text {; }}$ depth of layer, $10 \mathrm{~cm}$; cross section, $10.75 \mathrm{~cm}^{2}$.; weight, $67 \mathrm{~g}$.; mesh, 8 to 10 per in.; velocity of gas, $500 \mathrm{~cm}$. per min., air-chlorine ratio, 500 to 1 ; water content of air, 50 per cent saturation; pressure of gas above charcoal, 1 atmosphere; pressure of gas below charcoal, 1 atmosphere minus $0.85 \mathrm{~cm}$. water

VARIABLES: Temperature. Curve $E_{1}, 0.0^{\circ} ; \mathrm{E}_{2}, 12.0^{\circ} ; \mathrm{E}_{3}, 25.0^{\circ} ; \mathrm{E}_{4}$, $37.5^{\circ}$

The investigation at higher temperatures is now being carried on. By maintaining a slight reduction in pressure upon the charcoal, the reaction between water and chlorine is being studied in the vapor phase below $100^{\circ}$. The indications so far obtained are that, under these conditions with the water-vapor greatly in excess of the requirements, the chlorine can be completely converted to hydrogen chloride over long periods of time without changing the bed of charcoal catalyst and that the curve of production, after the initial rise, gradually falls off to a point where it remains comparatively flat.

INFLUENCE OF AMOUNT OF WATER-It is evident that an excess of water over that necessary to react with the chlorine is desirable. In Fig. 2 the curves of hydrogen chloride production are plotted for different moisture content of air, namely, $0,20,40$, and 80 per cent saturation. The curves showing the amourits of chlorine escaping unaltered at the same time are also shown.

It is to be noted that curve $F_{1}$ shows some production of hydrogen chloride with dry air. This is due to the fact that it was not found practicable to remove all moisture from the charcoal except by the progress of 
in

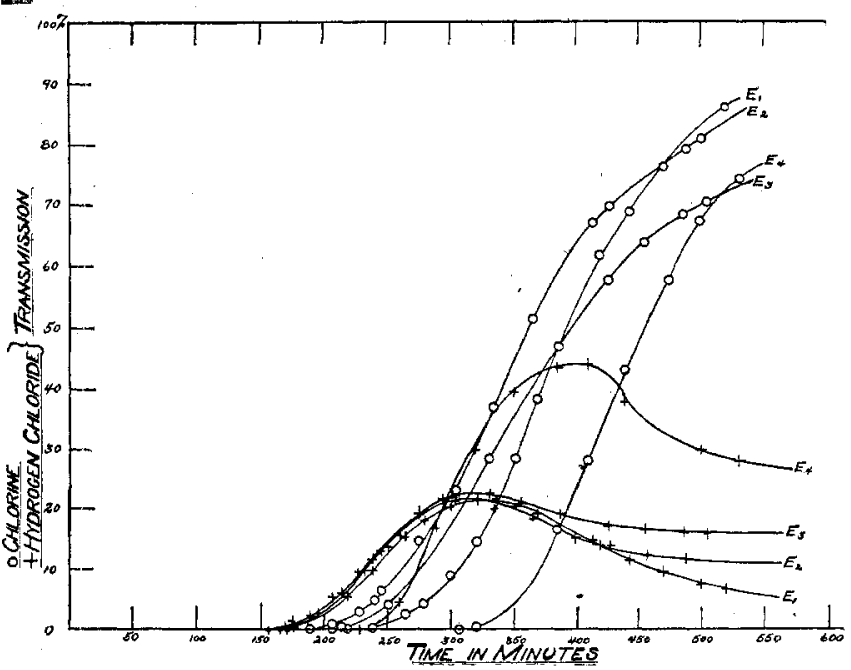

Fita. 2-Curves Showing the Production of Hydrogen Chloride (MARKED + ) AND AMOUNT OF ChLORINE (MARKED O) Escaping ACtion When Varying Amounts of Water Are Present

Constants: Charcoal E; depth of layer, $10 \mathrm{~cm}$; cross section, 10.75 $\mathrm{cm}^{2}$.; weight of charcoal, $67 \mathrm{~g}$.; mesh, 8 to 10 per in.; temperature, $25^{\circ}$; velocity of gas, $500 \mathrm{~cm}$. per minute; air-chlorine ratio, 500 to 1 ; pressure of gas above charcoal, 1 atmosphere

VARIABLES: Water content of air, $\mathrm{E}_{1}, 0 ; \mathrm{E}_{2}, 20 ; \mathrm{E}_{3}, 40 ;$ and $\mathrm{E}_{4}, 80$ per cent saturation

The molar ratios of water to chlorine are, $0: 1: 3.1: 1: 6.2: 1 ; 12.4: 1$

the reaction itself. The really significant parts of these curves are the ones indicating that the production of hydrogen chloride is in each case reaching a constant rate dependent upon the amount of water present. Later experiments conducted without air and with the water-vapor greatly in excess of the requirements of the reaction indicate that large-scale production of hydrochloric acid is possible by this method.

CATALYTIC VALUE OF DIFFERENT CHARCOALS-It is well known that different charcoals, and charcoals treated by different processes, have greatly varying powers of absorbing gases, and other substances such as dyes, colors, and impurities from solutions. It is also evident from the work of Bohart and Adams ${ }^{1}$ that different charcoals show great differences in the catalysis of the reaction between chlorine and water.

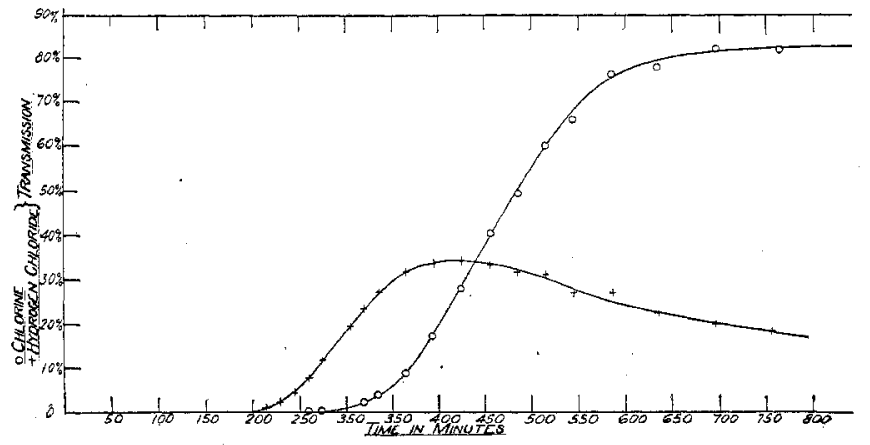

Fig. 3-Curves Showino the Production of Hydrogen Chloride (MARKed +) aNd AMount of Chlorine (Marked O)

Constants: Charcoal F; depth of layer, $10 \mathrm{~cm}$; cross section, 10.75 $\mathrm{cm}^{2}$.; weight of charcoal, $65 \mathrm{~g}$.; mesh, 8 to 10 per in.; temperature, $25^{\circ}$; velocity of gas, $500 \mathrm{~cm}$. per min.; air-chlorine ratio, 500 to 1 ; pressure of gas above charcoal, 1 atmosphere; pressure of gas below charcoal, 1 atmosphere minus $0.97 \mathrm{~cm}$. of water; molar ratio of water to chiorine $7.7: 1$

As an illustration of this fact the curve $E_{3}$, Fig. I, may be compared with the hydrogen chloride curve of Fig. 3.

1 Loc; cit.
The conditions of the experiments were identical in every respect except that the charcoals were different. Charcoal $\mathrm{F}$ shows a maximum hydrogen chloride production of 34 per cent, while Charcoal $\mathrm{E}$ reaches 26 per cent. The ctrrves fall off at the end of $800 \mathrm{~min}$. to $\mathrm{x} 8$ per cent in the case of $F$, and 7 per cent in the case of E. Other charcoals are known to show even greater differences at low temperatures. Accurate comparisons are not available at higher temperatures.

It is to be noted in Figs. I, 2, and 3 that the delay in the appearance of hydrogen chloride is due to the $<$ absorptive action of the charcoal on this gas and not to any induction period in the reaction.

\section{SUMMARY}

I-It is shown that the reaction between chlorine, water, and charcoal between $0^{\circ}$ and about $\mathrm{I}_{3} 0^{\circ} \mathrm{C}$. produces hydrogen chloride and carbon dioxide, and that the most important factors influencing the speed of the reaction are the character of the charcoal, the temperature, and the relation between the concentrations of the water and the chlorine.

2-A reversal of Deacon's process is discussed and it is interesting to note that changing industrial conditions have made it of possible commercial application.

\section{THE CORROSION OF BRASS IN DILUTE ELECTROLYTES ${ }^{1}$}

\section{By J. H. Reedy and Bertram Feuer}

DEPARTMEAT OF ChEMISTRY, UNIVERSITY OF ILLINOIS, AND WATER SURVEY Division, State of Illinois, URBana, Ill,inois

Received January 21, 1920

The corrosion of metals and alloys is conditioned by a number of influences, such as the composition of the metal, the dissolved substances present in the liquid in contact with it, temperature, stirring, dissolved oxygen, homogeneity, contact with metals and catalytic agents, the previous mechanical and thermal treatment of the metal, the nature of its surface, and so forth. In view of this large number of influences which are operative in the process of corrosion, and especially inasmuch as some of them are decidedly indefinite and hard to control, it is not surprising that the results and theories of corrosion are as diverse and conflicting as the literature shows them to be. The principle of studying each influence individually seems the most promising method of attack for this problem, and has been used in the present work.

A large amount of valuable work has been done on this problem, and the authors have freely availed themselves of the information already in the literature. Very noteworthy in this respect are the elaborate

1 This article is published as a more or less preliminary report. The writers are fully aware that certain phases of the probletn have been only superficially investigated, and others have been omitted altogether. It is planned to continte this study at a later time.

The Fourth Report of the Corrosion Committee of the Institute of Metals, written by Bengough and Hudson (J. Inst. Metals, 21 (1919), 37), was received after the experimental work of this paper was finished. It appears that part of the work of these investigators has been duplicated in our work and the conclusions that have been reached on certain points are identical. However, it has been deemed best to publish our paper in its original form, not only as a substantiation of the results of the above investigators, but particularly to present a unified account of our work which contains a large_amount of experiment and inference not covered in th. British paper. 